\title{
Larval Anisakis simplex B (Nematoda: Ascaridoidea) of short-finned squid (Cephalopoda: Ommastrephidae) in north-west Spain
}

\author{
S. Pascual*, A.F. Gonzalez ${ }^{\dagger}$ C. Arias* and A. Guerra ${ }^{\dagger}$ \\ *Laboratorio de Parasitología, Facultad de Ciencias del Mar, Universidad de Vigo, Apartado 874 Vigo, Spain \\ (e-mail: spascual@setei.uvigo.es). ${ }^{\dagger}$ Instituto de Investigaciones Marinas (CSIC), Eduardo Cabello 6, 36208 Vigo, Spain
}

\begin{abstract}
The role of the ommastrephid squids Illex coindetii and Todaropsis eblanae (Mollusca: Cephalopoda) collected from two areas in the north-eastern Atlantic waters (north-west Spain) as hosts for larval ascaridoid nematodes was examined from November 1992 to November 1993. The morphology, morphometric growth, population dynamics and electrophoretic identification of the anisakid nematodes was described. The correspondence of Anisakis type I larvae recovered from both squid species within the sibling species Anisakis simplex $\mathrm{B}$ is confirmed by comparative data on morphology, morphometry, and genetic evidences. Almost all somatic structures showed progressive and continuous allometric growth corresponding with increase in worm length. Seasonal changes in parasite population levels were evident in both sampling areas.
\end{abstract}

\section{INTRODUCTION}

The distribution of anisakid larvae in invertebrates has always been very uneven. Ignorance of the early larval stages and of the hosts in which they develop has resulted in uncertainty and confusion on the role the various invertebrate hosts play in the nematode life history (Smith, 1983; Hurst, 1984). Squid are not an exception to this pattern. Anisakid third stage larvae $\left(\mathrm{L}_{3}\right)$ have been reported widely in squid from the three major oceans and seas. That list indicates squid of almost all taxonomic and ecological divisions may be capable of harbouring the worm (i.e. indicate the capabilities of anisakines), but not the ecological realities of transmission which remain obscure for the group as a whole. The eurixeneous condition exhibited by food-transmitted $\mathrm{L}_{3}$ (Cheng, 1976; Smith \& Wootten, 1978; Smith, 1983) and the important role of oegopsid cephalopods in the trophic ecology of oceanic ecosystems (Clarke et al., 1993; Lipinski et al., 1992; Guerra et al., 1993) clearly suggest that all exploited squid may carry and transmit anisakines.

Up to date information of squid as hosts for nematodes has been well documented, although it is still confined to more or less fragmentary records of presence or absence (see review by Hochberg, 1990) with little if any biological interpretation of the results. This is due in part to difficulties in specific identification of larval anisakines in which few, if any, of the taxonomic characters used for adult identification are present in the developmental or larval stages. Additionally, the importance of intraspecific variation in the taxonomy of marine nematodes has also marked the abundant literature about unresolved taxonomic and nomenclature problems. Moreover, anisakid infections in cephalopods often are not supported by adequate large sample sizes (in a spatial and/or timescales), taxonomic descriptions, specific determination or generic placement, type material and quantitative studies on host-parasite relationships.
Data on morphology, morphometry, growth pattern, genetic and population dynamics of larval anisakine parasites in squid are provided herein. The results are discussed in relation to the biology of squid and to the life history and ecology of the nematodes.

\section{MATERIALS AND METHODS}

Specimens of Illex coindetii (Vèrany, 1839) and Todaropsis eblanae (Ball, 1841) (600 each) were collected randomly by fishermen at monthly intervals from two welldifferentiated hydrographic areas (Fraga et al., 1982) off the coast of Galicia $\left(42^{\circ} 05^{\prime}-45^{\circ} 15^{\prime} \mathrm{N} \quad 07^{\circ} 00^{\prime}-09^{\circ} 20^{\prime} \mathrm{W}\right)$ from November 1992 to November 1993 (Figure 1). Immediately upon capture commercial samples were placed on ice and transported to the laboratory where they were examined on arrival while still fresh. Each squid was sexed, weighed (g), and the dorsal mantle length (DML) was measured to the nearest millimetre. Maturation (condition of the gonad) was also assessed using a universal maturity scale (Lipinsky, 1979). All organs were examined for anisakine nematodes using a stereomicroscope. All larval nematodes were treated in the same manner to standardize the material for comparative purposes (Fagerholm \& Lovdahl, 1984). Specimens were washed in saline solution $(0.9 \% \mathrm{NaCl})$, fixed in Berland's fluid, cleared in lactophenol, stored in 1:9 solution of glycerin-70\% ethyl alcohol. Temporary mounts in glycerine jelly were used for light microscope examination. The head and tail of each larva was examined under bright field and phase contrast microscopy before and after clearing in lactophenol. Additional glutaraldehide-fixed specimens were prepared for SEM by dehydrating in an ethanol series, critical-point-dried in $\mathrm{CO}_{2}$ using a Polaron E3000, and sputter coated in a Polaron SC500 using 60\% gold-palladium. They were examined with a Philips XC30 SEM operated at 5-12 kV. 


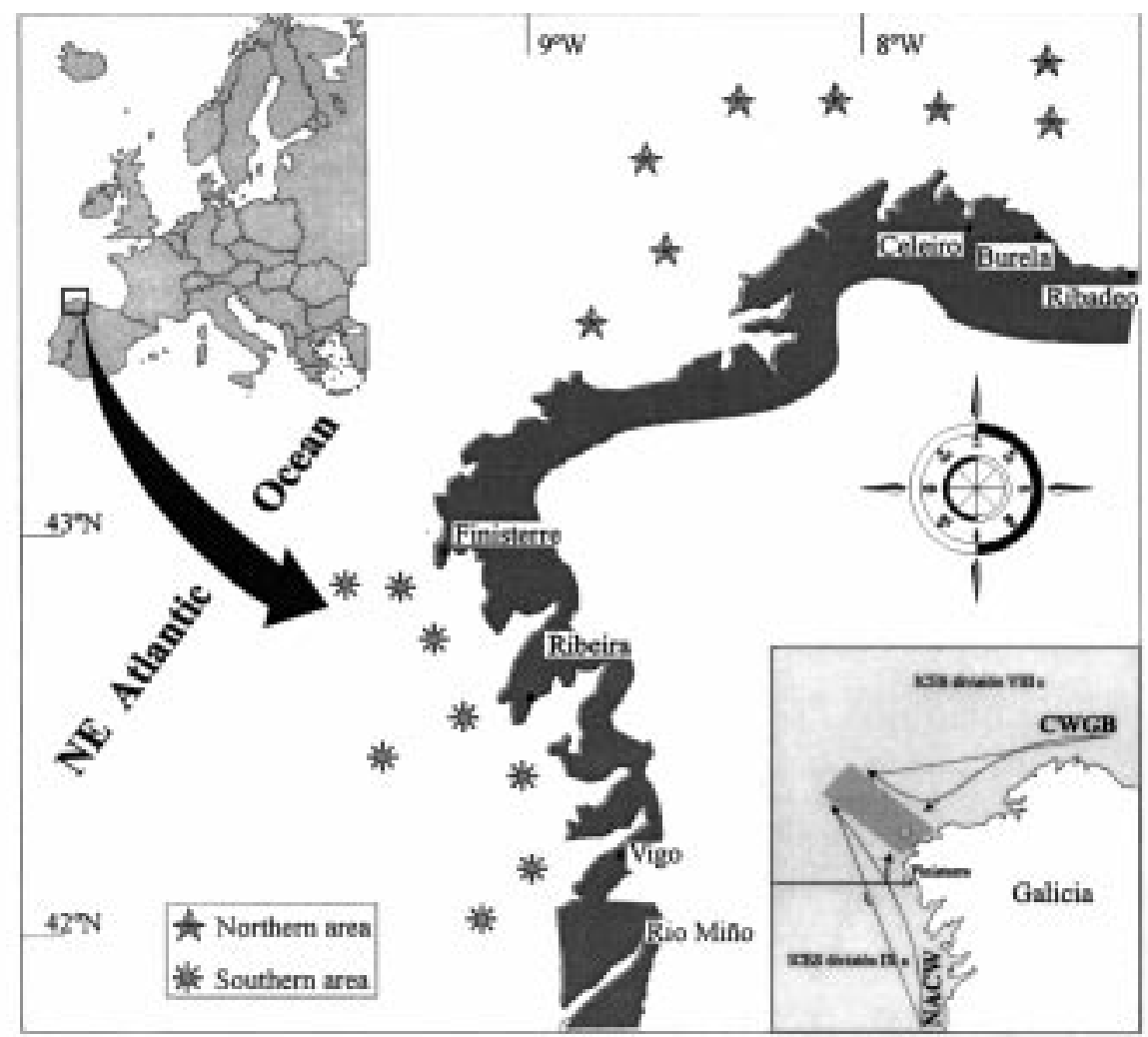

Figure 1. Location of sampling area showing trawl stations along the north-west Spanish Coast. Scheme of surface circulation of central water between 100 and $400 \mathrm{~m}$ depth is also included. The shaded area is the zone of lateral contact between NACW (North Atlantic Central Water) and the CWGB (Central Water of the Gulf of Biscay).

Subsequent decoating of specimens can be achieved if necessary.

Biomorphometric data were collected on 100 larvae (50 per host species) using Image Analysis System IBAS 2000. The following measurements were recorded on cleared specimens (Figure 2): total body length (BL), maximum body width (BW), proventriculus length (=muscular oesophagus) (PL), ventriculus length (=glandular oesophagus) (VL), ventriculus width (VW), intestine length (IL), mucron length (ML), and the distance from anus to tip of tail (AT). The total length of larger larvae was measured to the nearest $0.5 \mathrm{~mm}$. Measurements were standardized to assure that no bias was introduced during analysis. To enable comparison with other studies, the proportions of the various body parts to body length were also expressed as a percentage. Moreover, the values for all characters were transformed to logarithms to equalize variances and produce scale-invariant covariances that linearize allometric relationships. Growth pattern was calculated by use of the equation:

$y=a+b x$

where $\mathrm{x}=\mathrm{BL}, \mathrm{y}$ is the other measurement being related, $\mathrm{b}$ is the allometric factor and, $\mathrm{a}$ is the expected value of $\mathrm{y}$ at $\mathrm{x}=1$ (Gould, 1966).

The $r^{2}$ for the proportion of variance of the body parts and organs accounted for by the regression model and the $F$ for goodness of fit were determined. The $t$-test was used to discriminate host-induced variability in morphometric variables. In addition, a comparison of regression lines was assessed by means of analyses of covariance (ANCOVA).

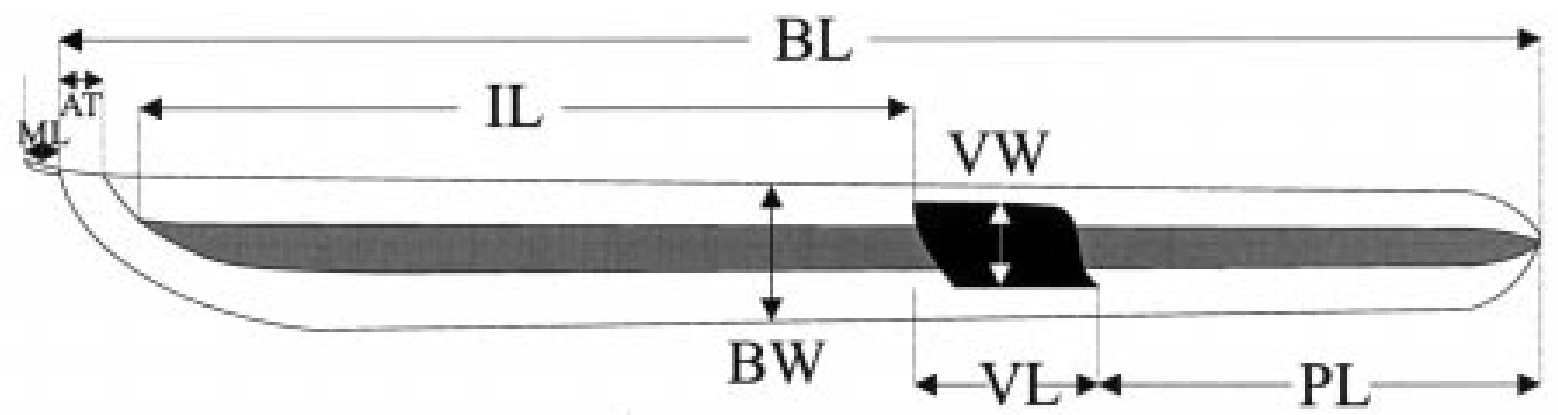

Figure 2. Anisakis simplex $\mathrm{B} \mathrm{L}_{3}$. (BL, total body length; BW, maximum body width; PL, proventriculus length; VL, ventriculus length; VW, ventriculus width; IL, intestine length; ML, mucron length; AT, distance from anus to tip of tail.) 
Seasonal occurrence of the worm was tested through significance of difference among logtransformed abundance among each season for both fishing areas of the range using one-way analysis of variance (ANOVA). To this end, data on the seasonal variations in infestations were analysed on a quarterly basis. The following seasonal samples were used: winter (January-March); spring (April-June); summer (July-September); and autumn (October-December). The variance to mean ratio of parasites was also calculated to provide an index of the degree of overdispersion of the anisakine in different months. The concepts denoted by the terms prevalence, mean intensity, abundance and relative density of infestation are defined in accordance with Margolis et al. (1982).

\section{RESULTS}

Taxonomic summary

Description of larvae (Figure 3)

Typically striated near head and posterior extremity but some worms striated along entire body length. Mouth triangular with trilobed dorsal lip and bilobed ventrolateral lips each with single indistinct papilla. Boring tooth located ventral to the mouth anteroventrally projecting. Excretory pore transverse slit situated between the ventrolateral lips, opens from a single excretory duct. Digestive tube simple (oesophagus-ventriculus-intestine). Oesophageal and intestinal appendages lacking. The ventriculus is rather long with a characteristic oblique posterior margin. Ventriculus-intestine junction skewed. Rectum opens at anus; three rectal glands present (two dorsal and one ventral). Postanal tail round, with a terminal mucron or spine. Reproductive organs not developed.

Hosts

Illex coindetii (Vèrany, 1839), Todaropsis eblanae (Ball, 1841) (Mollusca: Ommastrephidae).

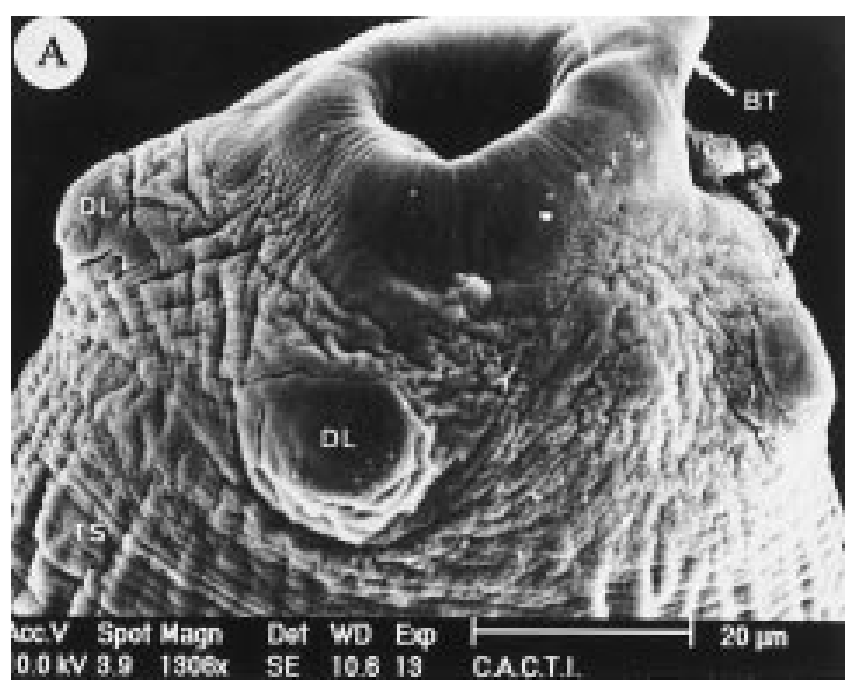

Locality

North-west Spain (north-east Atlantic Ocean).

\section{Site of infection}

Illex coindetii: (on the external wall of the stomach: 89) (on the gonads: $7.2 \%$ ) (free in the mantle cavity: $3.8 \%$ ); Todaropsis eblanae: (on the external wall of the stomach: 93.3\%) (on the gonads: $2.8 \%$ ) (free in the mantle cavity: $3.9 \%)$.

\section{Type specimens}

Vouchers (three slides containing $\mathrm{L}_{3}$ ) were deposited in the Department of Invertebrate Zoology, Santa Barbara Museum of Natural History, California, USA (catalogue nos. SBMNH-143034; 143056).

\section{Larval morphometrics}

Arithmetic mean values for morphometric data on larval Anisakis simplex recorded from several hosts in the north-east Atlantic Ocean, and the same measurements from both squid host species examined in the present study are given in Table 1 . Pearson correlation coefficients among larval measurements within each squid species are shown in Table 2. Larvae collected from I. coindetii were greater in overall length than those collected from T. eblanae, although the difference was not significant $(P>0.01)$. Larvae from T. eblanae were significantly greater in width than those from I. coindetii $(t=-5.063 ; \mathrm{df}=47 ; P<0.001$ for body width) $(t=-4.144 ; \mathrm{df}=49 ; P<0.001$ for ventriculus width). Larvae collected from both squid were greater in size than larvae from euphausiids, except larvae from Thysanoessa inermis in the northern North Sea, but were smaller than those from teleosts.

Within each squid species, in almost all body proportions, the correlation coefficients were statistically significant, showing a positive association between the total body length and the length of internal structures. This group of correlation coefficients may be regarded as homogeneous and a mean of 0.71 applies to larvae from

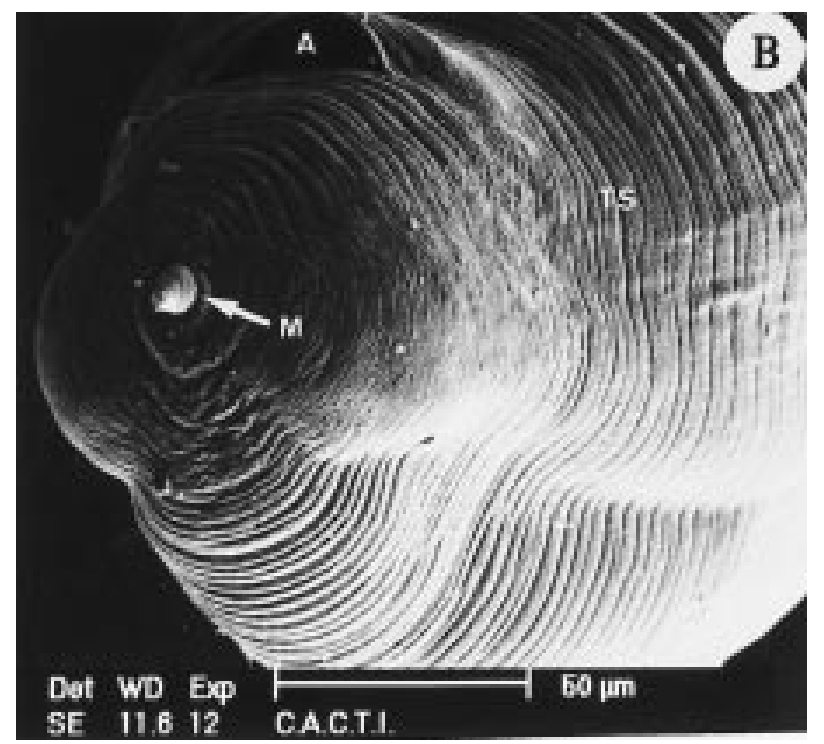

Figure 3. Anisakis simplex $\mathrm{B} \mathrm{L} \mathrm{L}_{3}$ : (A) anterior extremity, transverse striation (BT, boring tooth; DL, dorsal lip); (B) posterior end (tail) (TS, transverse striation; A, anus; $\mathrm{M}$, mucron). 
68 S. Pascual et al. Anisakis simplex B larvae in squid

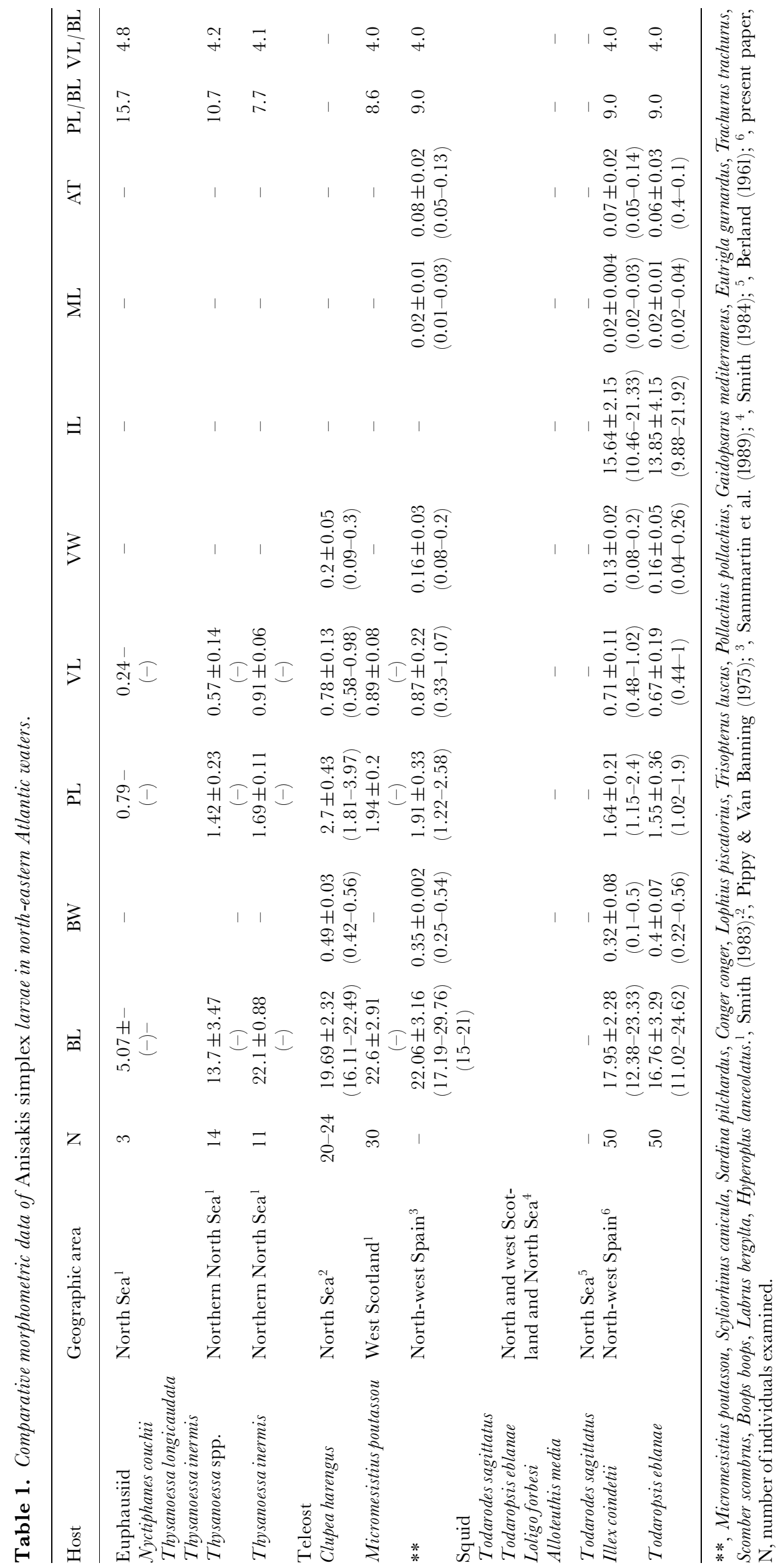


Table 2. Values of Pearson's correlation coefficients for larval measurements of Anisakis simplex $B$ in both short-finned squid species.

\begin{tabular}{lcccccc}
\hline Host & $\mathrm{N}$ & $\mathrm{BL}-\mathrm{BW}$ & $\mathrm{BL}-\mathrm{PL}$ & $\mathrm{BL}-\mathrm{VL}$ & BL-VW & BL-IL \\
\hline Illex coindetii & 50 & $0.58 * * *$ & $0.37 * * *$ & $0.51 * * *$ & $0.60 * * *$ & $0.99 * * *$ \\
Todaropsiseblanae & 50 & -0.06 & $0.59 * * *$ & $0.83 * * *$ & 0.08 & $0.99 * * *$ \\
\hline
\end{tabular}

$\mathrm{N}$, number of larvae; ***, $P<0.001$.

both hosts. However, considerable host-related variability exists in correlation coefficients of larval width characters.

\section{Growth pattern}

Where the variables fitted the model, almost all internal body measurements showed significant allometric growth with larval development $(P<0.01)$. Measurements of body structures are linear in relation to total body length. A significantly negative allometric relationship was observed between proventriculus length and body length in larvae from I. coindetii. Growth ranged from unity to strongly positive in the remainder structures (Table 3). Ventriculus width $\left(r^{2}=0.35\right)$ in larvae from I. coindetii and ventriculus length $\left(r^{2}=0.69\right)$ in larvae from T. eblanae were the variables that best fitted significant positive allometric growth. Ventriculus length (VL) (in worms from $I$. coindetii) and intestine length in those larvae collected from both squid hosts were almost isometrical with body length $(b=0.99)$, thus exhibiting similar growth rates. In addition, $r^{2}$ values of 0.99 suggest that a significant proportion of variance is accounted by the regression model. An interesting point arose from the fact that in larvae collected from I. coindetii, 'width' dimensions were positively noted as allometric, whereas in those larvae from T. eblanae 'length' dimensions were significant in that sense. However, some regression coefficients were low, particularly for mucron length and anus to tip of tail length. Widths of body structures versus body length was again the most important character that differentiates

Table 3. Regression values describing allometric growth patterns of Anisakis simplex $B$ larvae in squid.

\begin{tabular}{lcrrcrll}
\hline Variable & Host & $\mathrm{a}$ & $\mathrm{b}$ & $r^{2}$ adj & \multicolumn{1}{l}{$F$} & $\mathrm{df}$ & $P$ \\
\hline BW & IC & 12.648 & 16.584 & 0.303 & 22.290 & 1,48 & $* * *$ \\
& TE & 17.706 & -2.335 & 0.000 & 0.116 & 1,48 & $\mathrm{~ns}$ \\
PL & IC & 11.212 & 4.204 & 0.130 & 8.321 & 1,48 & $* *$ \\
& TE & -2.580 & 11.969 & 0.354 & 26.809 & 1,48 & $* * *$ \\
VL & IC & 10.243 & 10.920 & 0.253 & 17.576 & 1,48 & $* * *$ \\
& TE & 2.422 & 20.447 & 0.671 & 97.015 & 1,48 & $* * *$ \\
VW & IC & 9.829 & 61.143 & 0.372 & 30.007 & 1,48 & $* * *$ \\
& TE & 15.574 & 7.002 & 0.000 & 0.230 & 1,48 & $\mathrm{~ns}$ \\
IL & IC & 1.529 & 1.050 & 0.987 & 3651.518 & 1,48 & $* * *$ \\
& TE & 1.319 & 1.071 & 0.997 & 13841.54 & 1,48 & $* * *$ \\
TML & IC & 15.363 & 120.695 & 0.034 & 2.739 & 1,48 & $\mathrm{~ns}$ \\
& TE & 15.002 & 88.594 & 0.058 & 3.870 & 1,48 & $\mathrm{~ns}$ \\
AT & IC & 16.987 & 13.522 & 0.000 & 0.438 & 1,48 & $\mathrm{~ns}$ \\
& TE & 14.850 & 29.650 & 0.046 & 3.277 & 1,48 & $\mathrm{~ns}$ \\
\hline
\end{tabular}

$* *, P<0.01 ; * * *, P<0.001$; ns, not significant $(P>0.05)$; IC, Illex coindetii; TE, Todaropsis eblanae. larvae collected from I. coindetii and larvae collected from T. eblanae. Ratios of body and ventriculus widths against total body length were significantly smaller $(t=3.22$; $P<0.01)$ in those larvae from $I$. coindetii than those from T. eblanae. Table 3 showed where the significant differences exist between host species. However, slopes of regression lines for each character (PL, VL, IL) plotted against total body length (BL) did not differ among larvae from both squid hosts (ANCOVA: $F=1.94 ; P>0.1$ ).

\section{Genetic identification}

Using genetic evidence based on allozyme electrophoresis, Nascetti et al. (1986) showed that the isomorphic Anisakis simplex complex consisted of two sibling species provisionally designated $A$. simplex $\mathrm{A}$ and B. Type A occurred mainly in the Mediterranean, whereas Type B was widely distributed in the northeastern Atlantic Ocean. To confirm the species identification of the anisakines found in this study, several specimens from both squid species were sent to Professor L. Paggi and co-workers at the University of Rome, 'La Sapienza', Rome, Italy, for analysis. Their findings indicated that all nematode parasites of squid in this study can be positively identified as the common species A. simplex $\mathbf{B}$.

\section{Population dynamics}

A clear pattern of seasonal change in larval infection was evident. Figure 4 illustrates the observed monthly variations in prevalence, mean intensity, and relative density of infestation. In both northern and southern sampling areas, overall demographic parameters of infestation were significantly higher in the late winter and early spring periods than in the summer and autumn. Infestation values from the cold period (October-April) were five to eight times higher than those from the warmer period (May-October). This trend was amplified in the heavier infected northern area. There was also a consistent variation in geographic distribution. Over the entire year, squid examined from the northern area consistently had higher infection values than squid caught in the southern area. In larvae collected from I. coindetii in the northern area, mean intensity rose steadily during the autumn reaching a peaked pattern in March-May. Fluctuations between $0 \%$ prevalence in August to $60 \%$ in March, suggests a marked seasonal pattern of infestation (ANOVA: $F=5.848 ; P<0.001$ ). In comparison, in the southern area no seasonal pattern was observed (ANOVA: $F=0.438 ; P>0.1$ ). Demographic parasite parameters in the south were too low and similar throughout the sampling period. In T. eblanae, anisakid infestation 

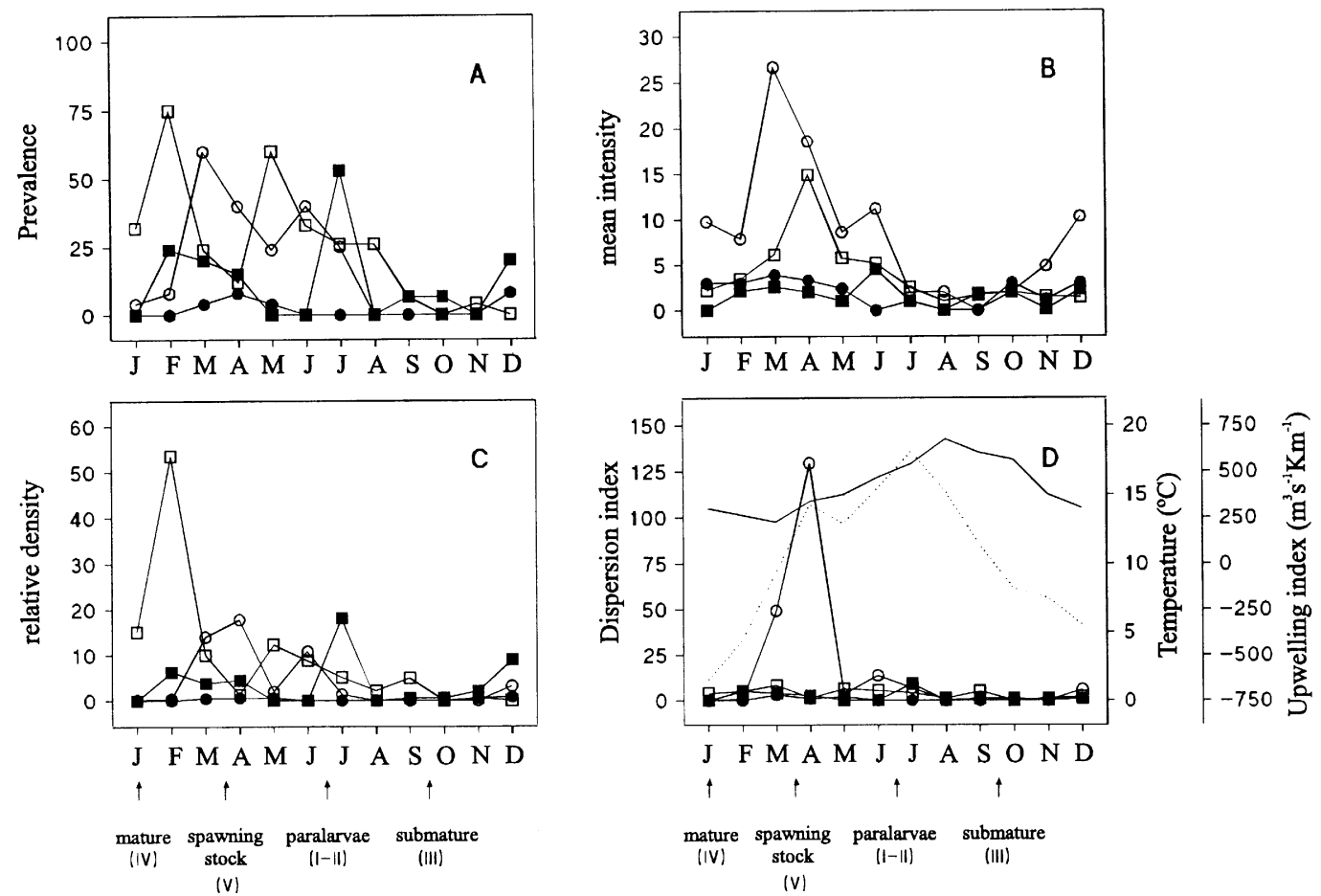

Figure 4. Figure 4. Monthly values in prevalence (A), mean intensity (B), density (C) and dispersion index (D) of Anisakis simplex $\mathrm{B} \mathrm{L}_{3}$ in squid at both sampling areas ( ICN, Illex coindetii from the northern area; O ICS, I. coindetii from the southern area; $\square$ TEN, Todaropsis eblanae from the northern area; $\square$ TES, T. eblanae form the southern area). The following squid samples were used: paralarvae (maturity stages I and II), submature (maturity stage III), mature (maturity stage IV) and the spawning stock (maturity stage V).

followed similar geographically-related trends. However, in this squid species the infestation was noted throughout the whole year. Mean intensity of infestation increased throughout the autumn, reaching a maximum value in springtime. This pattern suggests that infestation is also higher during colder months than in the warmer months. In the northern sampling area, abundance of infestation was statistically significant between seasons (ANOVA: $F=8.321 ; \quad P<0.01)$, but not in the southern area (ANOVA: $F=2.739 ; P>0.1$ ). In both squid species the highest values of relative density of infestation (up to 50 worms $\mathrm{kg}^{-1}$ ) were found in the largest mature squids. This pattern corresponds with highly aggregated infrapopulations (variance/mean $>1$ ) at squid spawning-time during the bloom of upwelling phenomena.

\section{DISCUSSION}

Larval populations of Anasakis simplex B from both squid species overlap considerably in size for all morphometric characters, although mean values indicate a marked heterogeneity in relation to the character of measure (i.e. length-width). The ranges and standard deviations of the characters also indicate considerable variation in size for both parasite infrapopulations. This fully agrees with considerable variability in allometric growth rates of parasites, depending upon the host species. Notwithstanding their geographic and host separation, the nematode specimens from all samples have no morphological or marked differences in growth patterns judged to be interspecific. Despite host-induced larval growth variations, genetic analyses have confirmed that the larvae constitute a single species. Observed differences presumably are due to heterogeneity in worm age. Host response to the presence of larvae may also play an important role in structuring parasite growth in the cephalopod-parasite system (Pascual et al., 1995a). The most obvious differences in measurements of Anisakis larvae from squid as compared with those from teleosts are seen in total body length (mean and range). In squid caught off Galicia, Anisakis larvae are smaller than those from teleosts. Such variation is unlikely to be caused by different methods of fixation, geographic or allometric variations (PL:BL and VL:BL ratios are identical among larvae collected from squid and teleosts off Galicia). Sizerelated differences in hosts are more likely responsible for the observed differences in parasite sizes (Pascual et al., 1995b). This suggests that comparative morphometric studies should be interpreted with caution because of the wide variation in host-sample characteristics.

The importance of squid as hosts, as compared with teleosts, may relate to the short life cycles and a monocyclic pattern of semelparity. Growth of larval Anisakis possibly continues until the squid is consumed by other paratenic or final hosts. A marked peak in the aggregated distribution of anisakid parasites in the squid from the heavily infected northern sampling area indicates that whole-parasite recruitment takes place at the same time. The overdispersion of parasite infrapopulations is leading by a selective accumulation factor at the individual level resulting from feeding pattern of larger and mature squid. At the time of infestations, the squid are mainly piscivorous. In the process of feeding on fish, principally the blue-whiting Micromesistius poutassou, they accumulate 
large number of larvae from that heavily infected prey (Sanmartin et al., 1989). The results indicate that seasonal and geographical variations in Anisakis infestation is not a recurrent one since it appears not to be stable over time within host populations. A variety of ecological and host related factors accounts for the variations in seasonal behaviour of the worm and between-site variation in infestation observed in this study. Changes in the trophic level occupied by squid, which is closely related to ontogenetic changes (González, 1994); and in habitat utilization patterns (Forsythe, 1993), clearly suggest that the whole host life cycle influence dissemination of foodtransmitted infective stages. This pattern appears to be common for wide-ranging generalist helminth species in which dissemination of infective stages is linked to host life cycle (Kennedy, 1982).

Off Galicia, recruitment of Anisakis larvae did not occur throughout the whole year. Nematode larvae were the most abundant during a short time of the year (cold period). According to data from morphometric and population dynamic analyses, seasonality may be probably attributed to squid movement from an inshore habitat to an offshore infected area during the spawning run. The hypothesis of a migration factor may also affect the interpretation of biological data, as has been observed for other ommastrephid species (Nigmatullin, 1989).

Geographic isolation of separated anisakid groups also is unlikely. Water masses off Galicia are relatively heterogeneous in physical properties, therefore distinctly separate spawning sites are more likely. Differences in values of infestation between the northern and southern sampling areas may be related to differences in habitat structure (Sousa \& Grosholz, 1991) bottom type (Smith, 1983); species biodiversity and biomass of neighbouring intermediate (mainly euphausiids) and paratenic hosts; trophic ecology; and climatic variables (wind speed and direction) which affect seasonal hydrographic patterns (upwelling). All those factors have been stressed as factors influencing sedimentation rates of Anisakis eggs (Smith, 1983). The apparent absence of infestation in squid from the southern area may therefore be explained by the existence of alternative intermediate hosts outside offshore depth contour; by a dilution factor provided by a higher biomass of potential first intermediate hosts; and/or by the influence of heavier seasonal upwelling cycles on parasite recruitment success. In addition, it is also likely that final hosts (marine mammals; González et al., 1994) avoid major upwelling events in inshore waters off the southern area where seasonal hydrographic phenomena determine the stability of trophic ecology of the area. Still there is a large number of cephalopod host species which may help us to explain the wide distribution of A. simplex $B$ larvae in the Atlantic Ocean.

We are specially indebted to Dr F.G. Hochberg (Department of Invertebrate Zoology, Santa Barbara Museum of Natural History, California, USA) for his patience, encouragement and critical reading of earlier drafts. We also wish to thank Dr Lia Paggi and co-workers at the Instituto di Parassitologia (Universitá degli Studi di Roma, La Sapienza, Italia) for their invaluable help with the molecular identification of the anisakid nematodes. Thanks are also due to Ministerio de Educación y Ciencia for providing financial support under project CICYT, MAR95-1919-C05-03.

\section{REFERENCES}

Berland, B., 1961. Nematodes from some Norwegian marine fishes. Sarsia, 2, 1-50.

Clarke, M.R., 1986. Cephalopods in the diet of Odontocetes. In Research of dolphins (ed. M.M. Bryden and R.J. Harrison), pp. 281-321. Oxford: Clarendon Press.

Clarke, M.R., Martin, H.R. \& Prince, P.A., 1993. The diet of sperm whales (Physeter macrocephalus Linnaeus, 1858) off the Azores. Philosophical Transactions of the Royal Society B, 339, 67-82.

Cheng, T.C., 1976. The natural history of anisakiasis in animals. Journal of the Milk Federation Technology, 39, 32-46.

Fagerholm, H.P. \& Lovdahl, M., 1984. Induced morphometric variation in the preparation of nematode parasites for the LM and SEM, pp. 245-247. Toronto: ICOPA-V.

Forsythe, J.W., 1993. A working hypothesis of how seasonal temperature change may impact the field growth of young cephalopods. In The recent advances in cephalopod fisheries biology (ed. T. Okutani et al.), pp. 133-143. Tokyo: Tokai University Press.

Fraga, F., Mouriño, C. \& Manriquez, M., 1982. Las masas de agua en las costas de Galicia. Resultados de Expediciones Cientfficas, 10, 51-77.

González, A.F., 1994. Bioecologffa de Illex coindetii (Vêrany, 1839) (Cephalopoda, Ommastrephidae) de las aguas de Galicia. Tesis Doctoral, Universidad de Vigo, Spain.

González, A.F., López, A., Guerra, A. \& Barreiro, A., 1994. Diets of marine mammals stranded on northwestern Spanish Atlantic coast with special reference to Cephalopoda. Fisheries Research, 21, 179-191.

Gould, S.J., 1966. Allometry and size in ontogeny and phylogeny. Biological Reviews, 41, 587-640.

Guerra, A., Simón, F. \& González, A.F., 1993. Cephalopods in the diet of the swordfish, Xiphias gladius, from the northeastern Atlantic Ocean. In The recent advances in cephalopod fisheries biology (ed. T. Okutani et al.), pp. 159-164. Tokyo: Tokai University Press.

Hochberg, F.G., 1990. Diseases of Mollusca: Cephalopoda. In Diseases of marine animals. Vol. III. Cephalopoda to Urochordata (ed. O. Kinne), pp. 47-227. Hamburg: Biologisches Anstalt Helgoland.

Hurst, R.J., 1984. Marine invertebrate hosts of New Zealand Anisakidae (Nematoda). New Zealand fournal of Marine and Freshwater Research, 18, 187-196.

Kennedy, C.R., 1982. Biotic factors. In Parasites, their world and ours (ed. D.F. Metrick and S.S. Desser), pp. 293-302. Amsterdam: Elsevier Biomedical Press.

Lipinsky, M.R., 1979. Universal maturity scale for the commercially-squids (Cephalopoda: Teuthoidea). The results of maturity classification of Illex illecebrosus (LeSueur, 1821) populations for the years 1973-1977. ICNAF Research Documents, 79/ II $/ 38$.

Lipinsky, M.R. Payne, A.I.L. \& Rose, B., 1992. The importance of cephalopods as prey for hake and other groundfish in South African waters. South African Fournal of Marine Science, 12, 651-662.

Margolis, L., Esch, G.W., Holmes, J.C., Kuris, A.M. \& Schad, G.A., 1982. The use of ecological terms in parasitology. Journal of Parasitology, 68, 131-133.

Nascetti, G., Paggi. L., Orecchia, P., Smith, J.W., Mattiucci, S. \& Bullini, L., 1986. Electrophoretic studies on the Anisakis simplex complex (Ascaridida: Anisakidae) from the Mediterranean and the north east Atlantic. International Journal for Parasitology, 16, 633-640.

Nigmatullin, C.M., 1989. Las especies de calamar más abundantes del Atlántico sudeste y sinopsis sobre la ecología del calamar Illex argentinus. Frente Maritimo, 5, 71-81.

Orecchia, P., Paggi, L., Mattiucci, S., Smith, J.W., Nascetti, G. \& Bullini, L., 1986. Electrophoretic identification of larvae 
and adults of Anisakis (Ascaridida: Anisakidae). Fournal of Helminthology, 60, 331-339.

Pascual, S., González, A., Arias, G. \& Guerra, A., 1995a. Histopathology of larval Anisakis simplex B (Nematoda, Anisakidae), parasites of short-finned squid in the SE North Atlantic. Bulletin of the European Association of Fish Pathologists, 15, 160-161.

Pascual, S., González, A., Arias, C. \& Guerra, A., 1995b. Helminth infection in the short-finned squid Illex coindetii (Cephalopoda, Ommastrephidae) off NW Spain. Diseases of Aquatic Organisms, 23, 71-75.

Pippy, J.H.C. \& Van Banning, P., 1975. Identification of Anisakis larva (I) as Anisakis simplex (Rudolphi, 1890, det. Krabbe, 1878) (Nematoda: Ascaridata). Fournal of the Fisheries Research Board of Canada, 32, 911-914.

Sanmartín, M.L., Quinteiro, P. \& Ubeira, F.M., 1989. Nematode parasites of commercially important fish in NW Spain. Diseases of Aquatic Organisms, 7, 75-77.

Smith, J.W., 1983. Anisakis simplex (Rudolphi, 1809 det. Krabbe, 1878) (Nematoda: Ascaridoidea). Morphology and morpho- metry of larvae from euphausiids and fish, and a review of the life-history and ecology. Fournal of Helminthology, 57, 205224.

Smith, J.W., 1984. Larval ascaridoid nematodes in myopsid and oegopsid cephalopods from around Scotland and in the northern North Sea. Fournal of the Marine Biological Association of the United Kingdom, 64, 563-572.

Smith, J.W. \& Wootten, R., 1978. Anisakis and anisakiosis. Advances in Parasitology, 16, 93-163.

Sousa, W.P. \& Grosholz, E.D., 1991. The influence of habitat structure on the transmission of parasites. In Habitat structure: the physical arrangement of objects in space (ed. S. Bell et al.), pp. 301-324. London: Chapman \& Hall.

Suzuki, T. \& Ishida, K., 1979. Anisakis simplex and Anisakis physeteris: physicochemical properties of larval and adult haemoglobins. Experimental Parasitology, 48 225-234.

Submitted 1 April 1996. Accepted 26 February 1998. 